\title{
ACTION AND CRIME: A FINE-GRAINED APPROACH
}

\section{Alvin I. Goldman†}

There is much to admire in Michael Moore's comprehensive and resourceful treatment of the philosophy of action in the context of criminal law. I am impressed by the degree to which he finds classical metaphysical issues in the theory of action to be germane to the interpretation and systematization of the criminal law. Many of his positions strike me as plausible and well-defended, including his causal-volitional approach to the nature of action. The main topic on which he is not convincing is the defense of the coarsegrained view of act-token individuation, or what he calls the "exclusivity thesis." 2

According to this thesis, all complex act-tokens are identical to basic act-tokens, which are bodily movements. For example, the complex act-token of Smith's killing Jones is identical to the basic act-token of Smith's curling his finger (thereby firing a gun at Jones). It is granted, of course, that the act-type killing is different from the act-type curling one's finger. But a particular act of killing is always identical to some particular bodily movement, according to the coarse-grained theory.

This contrasts with the fine-grained theory, which maintains that the above-mentioned act-tokens of Smith are two different, though intimately related, actions. ${ }^{3}$ Although the coarse-grained view is a widely respected contender in the theory of action and is imaginatively applied by Moore to the legal context, it suffers from a number of serious problems. Some of these Moore does not address, and others are more damaging than he appreciates. I shall present a case for the superiority of the (extreme) fine-grained view. In addition to its purely metaphysical virtues, this approach is helpful in the criminal law, especially for handling the notion of an offense.

† Professor of Philosophy, University of Arizona. B.A. 1960, Columbia University; Ph.D. 1965, Princeton University. I thank Thomas Hudson for valuable research assistance and extremely helpful comments on an earlier draft.

2 See Michael S. Moore, ACt AND CRIME: The Philosophy of Action and ITS IMPLICATIONS FOR CRIMINAL LAW (1993).

${ }^{2} \mathrm{Id}$. at 109-12, 280-301.

"In this Article, the terms "act" and "action" are used interchangeably, as they are by Moore. 
Six types of problems for the coarse-grained view have been presented in the literature: ${ }^{4}$ (1) the problem of effects, (2) the problem of causes, (3) the problem of modifiers, (4) the problem of the by-relation, (5) the time problem, and (6) the spatial location problem. Moore pays a good bit of attention to problems (5) and (6), and he tries to show how they can be handled from a coarsegrained perspective, but he gives little or no attention to the first four problems. I shall exposit and discuss these problems in order.

All six problems have the same general form. Whereas the coarse-grained view is committed to the identity of many "pairs" of act-tokens, there often appear to be properties that one member of a pair possesses and the other member lacks. But if the acts differ on any property, they cannot be identical, according to the Indiscernibility of Identicals principle. ${ }^{5}$ Thus, unless the appearance of property disparity can be explained away, the identity claim implied by the coarse-grained view, and hence that view itself, is unsustainable.

\section{The Problem of EFFECTS}

The first type of problem, the problem of effects, starts with the assumption that acts have causal properties, such as producing certain effects, results, or consequences. Suppose Ned plays the piano, and his playing causes Dolly to fall asleep and Molly to wake up. In virtue of these two effects, Ned can be credited with the complex act of putting Dolly to sleep and the complex act of waking Molly up. It is agreed, then, that there are the following act-tokens: Ned's playing the piano (act $A$ ), Ned's putting Dolly to sleep (act $A^{\prime}$ ), and Ned's waking up Molly (act $A^{\prime \prime}$ ). The coarse-grained view holds that these acts are one and the same: they are all identical to certain basic acts of Ned, viz., his moving his hands and fingers at a certain time and place, and hence identical to one another. But can these identities be sustained? By hypothesis, Ned's playing the piano (act $A$ ) has the property of causing Molly to wake up. But his putting Dolly to sleep $\left(A^{\prime}\right)$ appears to lack this property: it seems false to say that Ned's putting Dolly to sleep causes Molly to wake up, since this wrongly suggests that Dolly's falling asleep is somehow

${ }^{4}$ Relevant sources will be cited as the problems are discussed in turn.

${ }^{5}$ This principle says that if "two" objects, $X$ and $Y$, are really one and the same object, they must have all properties in common. Any discrepancy between the properties possessed by $X$ and those possessed by $Y$ indicates that they are not strictly one and the same object. 
causally implicated in Molly's awakening. That is not the intended scenario. Dolly and Molly are in separate rooms, and their states are unaffected by one another. Analogously, although act $A$ has the property of causing Dolly to fall asleep, act $A^{\prime \prime}$ appears to lack this property. Hence, $A$ is not identical to either $A^{\prime}$ or $A^{\prime \prime}$, contrary to the coarse-grained view. ${ }^{6}$

Moore gives brief attention, though only in a footnote, to this dilemma." His remarks occur in the context of a larger discussion of one of Judith Thomson's temporal-order problems. ${ }^{8}$ Thomson points out the oddity of saying " $A$ 's killing of $B$ caused $B$ to die several hours later." Moore insists that the killing does occur before the dying, and he explains the oddity of the quoted sentence as a merely pragmatic feature of the usage. He observes that " $[\mathrm{i}] \mathrm{t}$ is like saying that the most discussed event of the decade (referring to a large flood) caused more discussions to take place about it over the next ten years than about any other event." ${ }^{n 9}$ When a predicate repeats information already conveyed in a sentence's subject, as in this example, pragmatic oddity results. Moore proposes to diagnose my causal-effect cases in the same way. He acknowledges the oddity in saying that a defendant's killing of a victim caused the defendant's gun to fire, but still maintains that the killing of the victim did cause the defendant's gun to fire. Apparently he would offer the same response to the piano case: Ned's putting Dolly to sleep does have the property of causing Molly to wake up, and his awakening Molly does have the property of putting Dolly to sleep, though it sounds odd, given a full description of the circumstances, to say these things. The problem of effects, he wishes to conclude, is not an insuperable one for the coarse-grained view.

Moore's explanation, however, simply does not work for the piano example, or for many other such examples. The descriptor "Molly's waking up" does not repeat any information contained in the subject expression "Ned's putting Dolly to sleep." So no appeal

6 This sort of example is presented in ALVIN I. GOLDMAN, A THEORY OF HUMAN ACTION 2-3 (1970) [hereinafter GOLDMAN, HUMAN ACTION] (asserting the fine-grained theory of acts, which allows for differentiation of closely related acts); see also Alvin I. Goldman, The Individuation of Action, 68 J. PHIL. 761, $761-74$ (1971) [hereinafter Goldman, Individuation].

${ }^{7}$ See MOORE, supra note 1, at 289 n.19 (discussing the criticism of the coarsegrained view).

${ }^{8}$ See Judith J. Thomson, ACTS AND OTHER Events 47-50 (1977) (demonstrating how acts may be differentiated based on the order in which they occurred).

${ }^{9}$ MOORE, supra note 1 , at 288. 
to repetition can explain the oddity in question. Of course, Moore may not restrict pragmatic oddity to repetition, but he does not identify any other source of pragmatic oddity that would cover the present case. The situation, then, is as follows: if we take the correctness of the coarse-grained theory as a premise, we can infer that Ned's putting Dolly to sleep does cause Molly's waking up, because Ned's putting Dolly to sleep is identical with his playing the piano, which causes Molly's waking up. It would then follow that the oddity of saying this is not a semantical oddity but merely some sort of pragmatic oddity. But since the correctness of the coarsegrained theory is precisely the issue in dispute, its correctness cannot be taken as a premise. Moore needs some independent explanation of the oddity in some familiar pragmatic terms. In the absence of such an explanation, the statement's falsity is the most natural account of its oddity. If the statement is false, however, as we seem forced to conclude, then there is no complete sharing of properties, and Ned's putting Dolly to sleep is not identical to his playing the piano, or to his moving his hands and fingers at the relevant time and place.

\section{The Problem of Causes}

The second problem arises not from the effects of acts, but from their causes. There are cases in which one member of a pair of putatively identical acts has the property of being partially caused by a specific factor $F$, whereas the second member lacks the property of being partially caused by $F$. I originally gave the following case to illustrate this difficulty. ${ }^{10}$ John answers the phone and says "hello." He has just been quarreling with his wife and is in a tense emotional state. As a result, he unintentionally says "hello" very loudly. Consider now the following "pair" of acts: John's saying "hello" and John's saying "hello" very loudly. According to the coarse-grained theory, these acts are identical. Hence, they should share all of the same properties. But John's act of saying "hello" very loudly is partially caused by his tense emotional state, whereas John's act of simply saying "hello" is not partially caused by this emotional state. The absence of causal connection in the second case is supported by the absence of a relevant counterfactual, or "but-for," condition. It is false that if he had not been tense, he would not have said "hello." On the

${ }^{10}$ See Goldman, Human Action, supra note 6, at 3. 
contrary, he would have said "hello" anyway, even if he had not been tense or upset. So the act of saying "hello" very loudly possesses a relational property that the act of saying "hello" lacks, and they cannot be identical. A similar example is given by Fred Dretske:

My tug on the steering wheel of my car, for instance, doesn't cause my car to move, much less to move at $63 \mathrm{mph}$. Rather, it causes the 63-mph movement to be in that direction. My heavy foot is responsible for the speed, the dirty carburetor for the intermittent pauses, and the potholes in the road for the teeth-jarring vertical component of the movement."

This example is best construed as focusing on an event (rather than an action): the movement of the car. In the coarse-grained view, there is just one event here. The various descriptions "the car's moving," "the car's moving at $63 \mathrm{mph}$," and "the car's moving in that direction" all refer to one and the same event. But this is problematic for the reasons Dretske indicates. The car's moving in that direction is partly caused by my tug on the steering wheel, but this does not even partly cause the car's moving (simpliciter) or the car's moving at $63 \mathrm{mph}$. Once again, identities implied by the coarse-grained view seem to be unsustainable.

Before turning to ways in which a coarse-grained theory might try to handle this difficulty, let us ponder the implications of accepting the nonidentities endorsed by the (extreme) fine-grained view by examining that view in more detail. Could John's saying "hello" really be a distinct act from John's saying "hello" very loudly, and could the car's moving, the car's moving at $63 \mathrm{mph}$, and the car's moving in that direction be three distinct events, as the finegrained approach maintains? The initial implausibility of these results may be dispelled by considering a.class of entities which metaphysicians have found necessary or useful to acknowledge and to which fine-grained act-tokens belong. This class of entities goes by various names, such as "individual accidents," "abstract particulars," "tropes," or "property exemplifications." Two examples of this category, outside the realm of action, are the whiteness of a particular sheet of paper and the snub-nosedness of Socrates (or the being white of that sheet of paper and the being snub-nosed of Socrates). The whiteness of a particular sheet of paper should not

$"$ FRed DRETSke, EXPlaininc Behavior: REASONS in a WORLd of CAuSES 30 (1988). 
be confused with the universal (or property) whiteness itself, for the universal is instanced by many things in the world, whereas the whiteness of the paper is instanced only by the paper. The paper's whiteness cannot exist apart from the particular piece of paper. Another instructive bit of terminology for this metaphysical category is Nicholas Wolterstorff's "cases." ${ }^{12}$ The whiteness of a particular piece of paper is a "case" or "instance" of the universal, whiteness; the snub-nosedness of Socrates is a "case" or "instance" of snubnosedness in general. It is plausible to hold that each case, trope, or property exemplification is a case of just one universal, or property, each. That is, the redness of a particular piece of paper is a case or instance of just the universal, redness, not of the universal, being colored, although of course redness is a "determinate" of the "determinable," being colored. Similarly, the squareness of a piece of paper is an instance of the property squareness, though not an instance of the property four-sidedness. Analogously, if John's saying "hello" and John's saying "hello" very loudly are tropes or "cases," it is plausible to say that the former is an instance of only one property, saying "hello," and the latter is an instance of only one property, saying "hello" very loudly. Again, the car's moving on a particular occasion is just an instance of the universal, moving; the car's moving at $63 \mathrm{mph}$ on the same occasion is just an instance of moving at $63 \mathrm{mph}$ (and not an instance of moving), and so forth.

A subtle but important distinction needed here is that between exemplifying a property and being an instance of, or case of, a property. ${ }^{13}$ A piece of paper, a substance, exemplifies the universal whiteness but is not an instance of it. In general, substances are not instances of universals in this technical sense of "instance." Only tropes, like the whiteness of the paper, are instances of whiteness. In addition to being instances of universals, tropes may also exemplify them. For example, the redness of a piece of paper may exemplify, or "have," the property of being caused by the paper's being dipped in red ink. The redness of the paper, however, is not an instance of this causal property; it is only an instance of redness. Similarly, in the account offered here, John's saying "hello" is an instance of just one property, saying "hello," although it can

${ }^{12}$ Nicholas WOLTERSTORFF, ON UNIVERSALS: AN ESSAY IN ONTOLOGY 130-41 (1970).

${ }^{13}$ See id. at 133-34; see also Goldman, Human ACTION, supra note 6, at 11 (distinguishing the exemplification and instancing of a property). 
exemplify numerous properties. Similarly, John's saying "hello" very loudly is an instance of just one property, saying "hello" very loudly, although it too can exemplify many other properties. I shall call the principle that each trope is an instance, or case, of exactly one property the "single instance" principle. If this principle is adopted, it is clear that in the action and event examples under discussion all the act-tokens and event-tokens are distinct from one another, because all are instances of properties that are distinct from one another.

Several contributors to the literature, including Moore himself, endorse something like the trope or property exemplification theory without endorsing the single instance principle. ${ }^{14}$ They claim that a property exemplification can be an instance of several properties. This is a perfectly intelligible position, and the metaphysical expressions "trope" and "property exemplification" do not have such an entrenched usage that we should complain about the terminology being employed in this alternate way. However, if rejection of the single instance principle is used to dispute the distinctness of John's saying "hello" and John's saying "hello" very loudly, or the distinctness of the car's moving, its moving at $63 \mathrm{mph}$, and its moving in that direction, then the trope (or propertyexemplification) theory can no longer resolve the problem of causes. A trope theory without the single instance principle cannot explain why the car's moving at $63 \mathrm{mph}$ and its moving in that direction have different sets of causes, or causal factors.

Here the coarse-grained theorist will complain that accommodation of the problem of causes is purchased at the price of proliferating act- or event-tokens, and that this result is too high a price to pay. Moore first complains about this price by talking of how "busy" the fine-grained approach makes us: "[T]he sticky wicket is to say that these are seven different particular acts that we do at the very same time. This seems to make even the laziest of us very busy!"15 On the fine-grained approach, however, busyness is not a matter of the number of act-tokens one performs. (That would not be a plausible account of busyness on any theory!) Instead, it is a matter of the energy, industry, exertion, or attentiveness that an action sequence consumes, and this bears no simple relation to the

${ }^{14}$ See MOORE, supra note 1, at 370; see also JONATHAN BENNETT, EVENTS AND THEIR NAMEs 94 (1988); Hugh J. McCann, Individuating Actions: The Fine-Grained Approach, 13 CAN. J. PHIL. 493, 497-99 (1983).

${ }^{15}$ MOORE, supra note 1 , at 111 . 
number of acts performed. On any theory, a person's mere twiddling of her thumbs or wiggling of her toes can be regarded as numerous act-tokens, but this need not make her very busy.

An apparently more serious problem is posed by Moore in the following passage:

Suppose that John kisses Mary tenderly on the cheek at noon of a given day. How many events took place ... ? On [Jaegwon] Kim's view [a fine-grained view], quite a few: there is the event of John kissing Mary tenderly on the cheek, the event of John tenderly kissing Mary, and the event of John kissing Mary on the cheek. This strikes most people as absurd; Mary got kissed only once by John, even if that event instantiated several distinct properties (of being a tender kiss, of being a kiss on the cheek, and of being a tender kiss on the cheek). ${ }^{16}$

If the extreme fine-grained approach did have the indicated consequence, it would indeed be in trouble. We certainly do not want to say that there is more than one kiss, or more than one kissing, on this occasion. But if we handle the fine-grained approach carefully, we do not have to get this counter-intuitive result. There is just one act-token of kissing (by John of Mary) on this occasion, that is, one instance of the act-type kissing. Admittedly, there are additional act-tokens of John such as his kissing (of Mary) tenderly, his kissing (of Mary) on the cheek, and so on. But none of these is an instance of precisely the act-type kissing; each is an instance of a distinct act-type. So we do not have multiple kissings, though we do have one kissing (of Mary), one kissing (of Mary) tenderly, and so on. ${ }^{17}$ Thus, the consequence we need to avoid is successfully avoided. ${ }^{18}$

${ }^{16}$ Id. at 370; $f$. BENNETT, supra note 14, at 82 ("If Bertram kicked Candice only once, most of us will infer that he gave her only one kick, but Kim must say that he gave her many-his clumsy kick, his hard kick, his kick on her shin, and so on.").

${ }^{17}$ I would say, however, that the phrase "John's tender kissing of Mary" denotes an instance of the type "kissing Mary" (rather than "kissing Mary tenderly"). In the phrase "John's tender kissing of Mary," "tender" picks out a property that John's kissing of Mary exemplifies, rather than picking out a different type of which the cited act is an instance, as we have in the phrase "John's kissing of Mary tenderly."

${ }^{18}$ A problem would remain, however, if we let different descriptions of the same patient or object of an action yield different act-types. Suppose, for example, that Mary is John's wife and also Trudy's mother. Then is John's kissing his wife a different act-token from John's kissing Trudy's mother? If we take this variant of the fine-grained approach, then we shall have multiple kissings by John on the same occasion. See Goldman, HUMAN ACTION, supra note 6, at 11. An alternative approach is suggested by Jaegwon Kim's treatment of the fine-grained approach, in which two event-tokens are the same if they involve the same objects, however these 
Another way that coarse-grained theorists attack the fine-grained theory is to accuse the latter of confusing acts, or events, with facts. This sort of objection is leveled by Jonathan Bennett, following Zeno Vendler. ${ }^{19}$ Both Vendler and Bennett distinguish between two kinds of sentence nominalizations: perfect and imperfect nominals. In the nominal expression "Quisling's betrayal of Norway," "betrayal" is perfectly a noun, whereas "betraying" in the gerundial expression "Quisling's betraying Norway" is a sort of noun that still has a verb alive and kicking in it. Vendler and Bennett claim that perfect nominals name events and actions, whereas imperfect nominals (favored by fine-grained theorists) instead name facts. Facts are indeed finely individuated, but not actions, which are what we are interested in. Thus, when fine-grained action theorists, or event theorists, talk about their favored entities, they are really talking about facts. Actions and events are coarse-grained kinds of entities.

Hugh McCann persuasively deflates this line of attack. ${ }^{20}$ Imperfect nominals like "Quisling's betraying Norway" or "John's singing the Marseillaise" do not name facts. The things they name have beginnings and endings, and they last for some period of time. Facts, on the other hand, do not have beginnings or endings and do not last for periods of time. It is wrong to say that the fact that Quisling betrayed Norway, or the fact that John sang the Marseillaise, began or ended at a certain time. Nor is it correct to say that the fact that Quisling betrayed Norway, or the fact that John sang the Marseillaise, had a particular duration. Facts are arguably true propositions, and propositions do not occur or last for any period of time, and do not begin or end. So the sorts of entities picked out by imperfect nominals are definitely not facts, even if their grain of individuation approximates that of facts. ${ }^{21}$ The claim that

objects are described or characterized. On that approach, John's kissing his wife is the same act-token (or event-token) as John's kissing Trudy's mother, and we avoid the prospect of multiple kissings. See Jaegwon Kim, Causation, Nomic Subsumption, and the Concept of Event, $70 \mathrm{~J}$. PHIL. 217, 222-36 (1973); Jaegwon Kim, Events as Property Exemplifications, in AcTION THEORY 159, 166-67 (Myles Brand \& Douglas Walton eds., 1976) [hereinafter Kim, Events].

${ }^{19}$ See BENNETT, supra note 14, at 26-31; ZENo VENDLER, Lincuistics IN PHILOSOPHY 122-31 (1967) (discussing differences between facts and acts).

${ }^{20}$ See McCann, supra note 14, at 500-01. McCann's reply is directed at another proponent of this line of criticism, Hector-Neri Castañeda. See Hector-Neri Castañeda, Intensionalily and Identity in Human Action and Philosophical Method, 13 Nous 235, 235-60 (1979). However, the same reply is appropriate for Bennett.

${ }^{21}$ Actually, Bennett himself seems to acknowledge this, when he distinguishes 
imperfect nominals merely denote facts has been regarded as significant by philosophers because we already knew that propositions are finely individuated. The question is whether any entities "in the world," any entities that partake in causal relations, have comparable fineness of grain. Imperfect nominals may denote finely-individuated entities, but if these merely turn out to be facts, the lesson for ontology is insignificant. Thus, McCann's point that these finely-individuated entities are not facts, but things of a more "worldly" and temporal nature, is important.

Having elucidated and defended the fine-grained approach in more detail, let us now return to the problem of causes and see whether the coarse-grained theory provides an alternate solution. Return to Dretske's driving case. Instead of saying that the car's moving, its moving at $63 \mathrm{mph}$, and its moving in that direction are distinct event-tokens, the coarse-grained approach can say that there is but a single event which has many aspects or facets. ${ }^{22}$ There is just one car movement, but it has multiple facets such as speed and direction which do not all share the same causes. Thus, the coarsegrained approach tries to circumvent the problem of causes by saying that it is not different acts or events, but different facets of a single act or event, that have different causes.

Although this account does avoid the need for finely-individuated acts, it does not get away from the ontological need for finelyindividuated tropes. After all, what are "aspects" or "facets" (of an event or piece of behavior), and how are they to be individuated? If these are to be the entities that are caused by preceding factors, they will have to be individuated very finely. The speed of the movement will have to be distinct from the direction of the movement, because the speed facet has different causes from the direction facet. So the kinds of entities needed are things like themovement-being-at-63-mph and the-movement-being-in-that-direction, which look very much like finely-individuated tropes of the sort which the fine-grained approach calls "event-tokens." Thus, we wind up with precisely similar sorts of entities as the fine-grained approach posits, the only difference being that the subjects of the tropes are now coarse-grained events rather than substances. It is important to notice that this approach cannot get away with saying

\footnotetext{
"that $[S]$ " nominals from imperfect gerundial nominals, and admits that the grammatical behavior of these types of expressions differ. BENNETT, supra note 14, at 7-8.
}

${ }^{22}$ Cf. DRETSKE, supra note 11 , at $30-31$. 
that the speed and direction of the driving are just properties rather than property instances, for properties themselves do not participate in causal relations. We cannot say that the universal "at 63 mph" is caused by the pressure of my foot on the accelerator, because universals are not caused by anything. It is only the moving at $63 \mathrm{mph}$, a trope or property instance, that is caused by factors like the pressure of my foot on the accelerator. ${ }^{23}$

\section{THE PROBLEM OF MOdIFIERS}

We turn now to the third problem for the coarse-grained view, the problem of modifiers. One of the tasks of event theory or action theory is to provide an analysis of the logical form of sentences ascribing events or actions. A particular way of executing this task has been proposed by Donald Davidson, a leading proponent of the coarse-grained theory. This approach initially looks as if it sustains and indeed favors the coarse-grained theory; certainly it was so conceived by Davidson. But as Terence Parsons and others have shown, it in fact raises some grave difficulties for the coarse-grained theory. ${ }^{24}$

Consider the sentence, "Brutus stabbed Caesar in the back with a knife." What is the logical form of this sentence? Although it contains no referring expression that purports to denote an event, it can be construed as implicitly asserting the existence of such an event. ${ }^{25}$ On Davidson's proposal, it can be paraphrased roughly as

${ }^{23}$ Some commentators worry about causal arguments for nonidentities on the grounds that causal relations may not be "extensional." "Believes that" is the standard illustration of a nonextensional context: a context in which expressions designating identical things need not be intersubstitutable. For example, even though "the mayor" and "the pickpocket" designate one and the same individual, the sentence "Oscar believes that the mayor is an upstanding citizen" may be true whereas the sentence "Oscar believes that the pickpocket is an upstanding citizen" is false. Some commentators have worried that "causes" is similarly nonextensional. Nowadays, however, most commentators concede that "causes" is an extensional context, at least when it is flanked by genuine event-referring expressions. See generally DONALD DAVIDSON, Causal Relations, in ESSAYS ON ACTIONS AND EVENTS 149. $62(1980)$. This article was instrumental in getting people to appreciate this. If this is correct, then differences in causal properties are legitimate threats to identity claims, as I have been arguing.

24 See Terence Parsons, Events in the Semantics of EnGlish 153-66 (1990) (noting that the coarse-grained view is probably not consistent with the underlyingevent view). The difficulties for the coarse-grained theory are not a major theme of Parsons's book; indeed, he claims to have only slight interest in the problem of event individuation. Nonetheless, the problems he and others have identified for the coarse-grained theory are serious.

${ }^{25}$ See generally DONALD DAvidson, The Logical Form of Action Sentences, in Essays 
follows: "There is an event $e$ such that $e$ is a stabbing, $e$ had Brutus as its agent, $e$ had Caesar as its object, $e$ was (done) in the back, and $e$ was (done) with a knife." Notice that in this paraphrase the modifiers "in the back" and "with a knife" are both predicated of the same existentially quantified event variable, $e$. This paraphrase and similar such paraphrases thereby hold out the promise of elucidating similar action sentences without proliferating actions or events. For example, consider the sentence, "John flipped the switch, thereby turning on a floodlight and alerting a burglar." This sentence might be paraphrased as, "There is an event $e$ such that $e$ is a switch-flipping, $e$ had John as its agent, $e$ caused a floodlight to go on, and $e$ caused a burglar to become alert." Here too the paraphrase invokes only a single action. There is nothing (so far) to suggest that John's flipping the switch, his turning on a floodlight, and his alerting a burglar are distinct act-tokens, as the finegrained approach would claim.

As Parsons points out, however, there is a clear problem for identifying these act-tokens that stems from their modifiers. ${ }^{26}$ Consider the act-token of John's alerting a burglar. This was done with the floodlight; in other words, it is a property of this act-token that it had the floodlight as its instrument. Next consider the acttoken of John's flipping the switch. This was not done with the floodlight; it lacks the property of having the floodlight as its instrument. Thus, we again have a putative identity between a pair of act-tokens which in fact violates the Indiscernibility of Identicals principle. This difficulty cannot be evaded by the account of logical form that coarse-grained theorists offer. According to their account, the modifier phrase "with the floodlight" expresses a property that holds of some action that is both a switch-flipping and a burglar-alerting. But this account does not get things right. Although it is true that the burglar-alerting is done with the floodlight, it is false that the switch-flipping is done with the floodlight. So there is no single action (in the present case) that is both a switch-flipping and a burglar-alerting.

Other such examples are readily produced. Suppose we have agreed that I shall signal that I am the secret agent by saying that I have come to pick up the garbage. Then, if I say that I have come to pick up the garbage, I thereby signal that I am the agent. The

ON ACTIONS AND EVENTS, supra note 23, at 105.

${ }^{26}$ See PARSONS, supra note 24, at 164-65. 
coarse-grained theory would of course maintain that the saying is the signaling; there is just one act-token here, not two. But there is ample reason to distinguish them. The signaling is secret, but the saying is not. (By openly saying that I have come for the garbage I secretly signal that I am the agent.) Furthermore, even if the saying is clumsy, the signal need not be clumsy. (Perhaps the agreed-on signal is to say clumsily that I came for the garbage.) Thus, "secretly" modifies the signaling but not the saying, and "clumsily" modifies the saying but not the signaling. So the saying and the signaling cannot be identical. ${ }^{27}$ Here I see no prospect at all for a satisfactory response from the coarse-grained theory.

\section{The By-Relation Problem}

The Indiscernibility of Identicals principle should be formulated in terms of relations as well as properties. If $A=A^{\prime}$, then if $A$ bears any relation $R$ to some object $B, A^{\prime}$ must also bear $R$ to $B$. If there is any disparity in such relationships, then $A$ and $A^{\prime}$ are not genuinely identical. ${ }^{28}$ The fourth problem for the coarse-grained view concerns a kind of relation that seems to be indicated in many action sentences, a relation that one act bears to another in being the "way," the "method," or the "means" by which the latter is executed. ${ }^{29}$ When we say, for example, "John alerted the burglar by turning on the floodlight," we seem to indicate that a certain acttoken of John's, his turning on the floodlight, is the way or method by which he performs another act-token, his alerting of the burglar. This "by-relation" or "way-relation" can be used to raise problems for the coarse-grained view.

According to the coarse-grained view, every complex action is identical with some basic action. In the burglar-alerting example, the basic action is John's moving his finger. Thus, John's alerting

\footnotetext{
${ }^{27}$ See id. at 158. A similar example was presented in my book $A$ Theory of Human Action. See Goldman, Human Action, supra note 6, at 4. Suppose I owe Smith two dollars. Reaching into my pocket for some cash, I discover two single-dollar bills and one two-dollar bill. I have a fondness for two-dollar bills, but I recall that Smith goes wild over them. So I repay him with the two-dollar bill. The coarse-grained theory holds that my act of repaying him is the same as my act of giving him the two-dollar bill. But the latter is supererogatory (above and beyond the call of duty), whereas the former is not.

${ }^{28}$ This formulation could have been used for the problems of effects and causes.

29 The terms "method" and "means" are less felicitous than "way" because the former imply something about the agent's intent or purpose, whereas the by-relation in question does not presuppose any purpose or intent by the agent.
} 
the burglar is allegedly identical to John's moving his finger (when it is poised on the light switch). Now we know that John's turning on the floodlight stands in the by-relation to his alerting the burglar. That is, his turning on the floodlight is the way by which he alerts the burglar. So if his alerting the burglar is genuinely identical to his moving his finger, then his turning on the floodlight must stand in the by-relation to his moving his finger. That is, his turning on the floodlight must be the way by which he moves his finger. But this last suggestion is absurd. There is no way by which he moves his finger (this being a basic act)-certainly not by turning on the floodlight! So of the two putatively identical acts, alerting the burglar and moving his finger, his turning on the floodlight has the by-relation to the former but not to the latter. Hence, the two acts are distinct rather than identical. ${ }^{\mathbf{3 0}}$

Consider a second example. Jasper is playing chess. At the time in question, he moves his hand $\left(A_{1}\right)$, thereby moving his queen to king-knight-seven $\left(A_{2}\right)$, thereby checkmating his opponent $\left(A_{3}\right)$, thereby giving his opponent a heart attack $\left(A_{4}\right)$. Act $A_{3}$, checkmating his opponent, stands in the by-relation to act $A_{4}$, giving the opponent a heart attack. If the coarse-grained theory is right, act $A_{4}$ is identical to act $A_{2}$, moving his queen to king-knight-seven. Hence, act $A_{3}$ must also stand in the by-relation to act $A_{2}$. But it is obviously wrong to say that Jasper moves his queen to king-knightseven by checkmating his opponent.

Adherents of the coarse-grained theory might try to evade these problems by denying that "by" governs descriptions of act-tokens in the relevant sentences. Parsons, among others, makes this suggestion. ${ }^{31}$ He points out: "['By'] does not seem to be an ordinary preposition taking ordinary [noun phrases] as objects." 32 For example, we do not say things like "John alerted the burglar by his turning on the floodlight," or "Mary paid the bill by the writing of the check." So perhaps the "by"-phraseology should be analyzed in some other way, not as expressing a relation between act-tokens.

Another possibility, also suggested by Parsons, is that "by" might create a nonextensional context; such contexts are infamous for

${ }^{30}$ The problem of the by-relation was first identified in my book $A$ Theory of Human Action, see GOLDMAN, HUMAN ACTION, supra note 6, at 5, though my present formulation of it differs slightly from the original one.

${ }^{31}$ See PARSONS, supra note 24, at 103.

${ }^{32}$ Id. 
violating the substitutivity of genuine identicals. ${ }^{33}$ But it is hard to find convincing evidence for this possibility, as Parsons acknowledges. ${ }^{34}$ He suspects, as I do, that "by" stands for an extensional relation between two acts, so that the argument does indeed prove that many pairs of acts alleged to be identical by the coarse-grained theory are actually different.

A third response to the by-relation argument is offered by Norvin Richards. ${ }^{35}$ Richards asks us to consider Gerald Ford, then the President of the United States and the most powerful American citizen. Although these are indisputably the same person, he is the most powerful American by virtue of being President, but he is not President by virtue of being the most powerful American. So there seems to be an "in-virtue-of"-relation, similar to the by-relation, which creates analogous difficulties for identifying the President with the most powerful American. But surely that President is (or was) the most powerful American. So there is clearly something wrong, Richards suggests, with my line of argumentation.

If I had tried to prove that the subjects or agents of the acts in my example were nonidentical, Richards would have a good case against me. But I was only trying to prove that the two acts are nonidentical. The analogous thesis for Richards's own example would be the thesis that Ford's being President of the United States is not the same state of affairs as Ford's being the most powerful American citizen; and I think that this thesis is pretty well supported by the considerations he adduces. There does indeed seem to be an "in-

${ }^{33} I d$.

${ }^{34}$ An argument for nonextensionality is presented, however, by Carl Ginet. See CARL GINET, ON ACTION 54 (1990). Ginet asks us to consider S's playing a C-major chord (at time $t$ ) and $S$ 's simultaneously playing a C, an E, and a G (at time $t$ ). Ginet says that the by-relation apparently holds here, because it would be correct to say that $S$ plays a C-major chord "by" simultaneously playing a $\mathrm{C}$, an $\mathrm{E}$, and a $\mathrm{G}$. But it is also true, says Ginet, that these two acts are identical. So the by-relation should hold in the opposite direction as well; but it does not, since it would be false to say that $S$ simultaneously plays a $\mathrm{C}$, an $\mathrm{E}$, and a $\mathrm{G}$ "by" playing a $\mathrm{C}$-major chord. Hence, the byrelation must be nonextensional. The flaw in this argument, I think, is Ginet's assumption that the two acts are identical. I suspect that they are distinct, though related via the "by" of composition or constitution. (Philosophers sometimes suggest that a particular statue is composed of, or constituted by, a hunk of marble but is not identical with that hunk of marble. The relation of composition or constitution appears to be an antisymmetric relation, for it is odd to say, conversely, that the hunk of marble is composed of, or constituted by, the statue.) This compositional byrelation is different from the one I am focusing on, which I have previously called the "by" of level-generation. See GoldMan, Human ACTION, supra note 6, at 20-21.

${ }^{35}$ See Norvin Richards, E Pluribus Unum: A Defense of Davidson's Individuation of Action, 29 PHIL. STud. 191, 191-98 (1976). 
virtue-of"-relation that distinguishes these states of affairs, just as the by-relation distinguishes John's moving his finger from his alerting the burglar.

Obviously, if the act-identities claimed by the coarse-grained view are rejected, we must at least provide for an intimate relationship between (or among) the different acts. This is precisely what the by-relation provides. In earlier works, I have tried to explain and systematize this by-relation. ${ }^{36}$ Although my positive account of the by-relation may have had some flaws, ${ }^{37} \mathrm{I}$ believe that there is a by-relation that stands ready to be analyzed. Whatever the details of such an analysis, we can depict the structural relationships of sets of act-tokens that are identical according to the coarsegrained view with the help of action diagrams. ${ }^{38}$ A diagrammatic treatment of the piano-playing example is presented below.

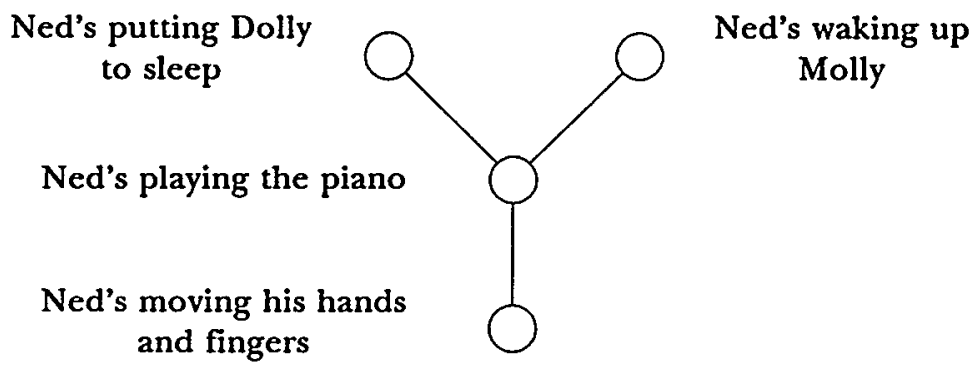

In this diagram circles represent act-tokens. A vertical or diagonal line connecting a lower circle to a higher circle indicates that the act-token represented by the former stands in the by-relation to the act-token represented by the latter. For example, Ned's putting Dolly to sleep is done by (his) playing the piano, and his playing the piano is done by (his) moving his hands and fingers. In other

\footnotetext{
${ }^{36}$ See Goldman, HUMAN ACTION, supra note 6, at 20-48; Goldman, Individuation, supra note 6, at 762-65, 773-74.

${ }^{37}$ See BENNETT, supra note 14, at 203-12 (arguing, inter alia, that my arguments hinge too much on the semantics of event-names and also that augmentationgeneration has no usefulness in the analysis, since for the theory to hold true logically independent truths must be equivalent); Michael Bratman, Individuation and Action, 33 PHIL. STUD. 367, 371-74 (1978) ("Goldman's relation of generation is insensitive to the distinction between performing an action and simultaneously undergoing a change as a result of an action one is performing."); Castaneda, supra note 20, at 246-51 (arguing that my analysis of level-generation fails to capture the intended formal properties of the by-relation).

${ }^{38}$ These were first presented in GOLDMAN, HUMAN ACTION, supra note 6, at 20-48.
} 
terminology I have introduced, we may say that his moving his hands and fingers level-generates his playing the piano, which in turn level-generates both putting Dolly to sleep and waking Molly up. The level-generational relation is clearly transitive; so Ned's moving his hands and fingers also level-generates his putting Dolly to sleep and his waking Molly up. As the diagram also indicates, not all pairs of acts belonging to such a set have the level-generational relation to one another (in either direction). Ned's putting Dolly to sleep does not level-generate his waking up Molly, nor vice versa, as our earlier discussion suggested. ${ }^{39}$ In general, sets of acts of this sort form a tree-like diagram with a basic act at the root. Thus, although the fine-grained view posits multiple acts where the coarsegrained view posits just one, the multiple fine-grained acts form a highly structured array, and the relationships composing this array are of considerable theoretical interest. ${ }^{40}$

\section{The Temporal and Spatial Problems}

The fifth and sixth problems, the temporal and spatial location of act-tokens, are dealt with much more extensively by Professor Moore, and what I shall say here is somewhat different from my thread of argumentation in the preceding Sections. I have a fair bit of sympathy with what Moore says about the temporal and spatial locations of acts. The main point I shall press is that these positions are equally available to the fine-grained theorist, contrary to what Moore claims.

Since the issues of space and time are quite analogous, it will suffice, I believe, to confine our attention to the temporal questions, because what we say there will carry over, mutatis mutandis, to the spatial domain. Briefly, fine-grained theorists usually say that a complex act such as a killing spans the time of the agent's basic act to the time of the victim's death. Call this the "long view" of a

${ }^{39}$ See supra part I.

${ }^{10}$ For an example, see Holly M. Sinith, Moral Ascription Theory (Dec. 24, 1993) (unpublished manuscript, on file with author), which explores the moral statuses of the various acts on a single act-tree. Some acts on an act-tree, for example, an act of keeping or breaking a promise, may have intrinsic moral rightness or wrongness. Other act-tokens on the same act-tree, especially lower acts on the tree, may "inherit" moral status from these. A linguistic utterance per se, for example, is presumably not intrinsically wrong, but if it level-generates an act of telling a lie, it may inherit moral wrongness from that higher act. Acts that "branch off" from the basic act, for example, frightening away a mosquito (by expulsion of breath), would not inherit moral wrongness even if they are on the same act-tree. 
killing. Since the basic action is commonly much shorter in duration, the correctness of the long view would clearly refute the coarse-grained theory, since the basic action and the killing would have different temporal properties. Coarse-grained theorists therefore favor a "short view" of a killing, and this clearly follows from their identification of any complex act like a killing with an appropriate basic action. It remains to be decided which is correct: the long view or the short view. Unfortunately, there are intuitive difficulties for each position.

Against the short view, we have Judith Thomson's argument that we cannot say that the victim's death occurs several hours after the defendant killed him. ${ }^{41}$ That sounds odd. Yet that is what the short view requires us to say. Against the long view, we have Moore's observation, following Donald Davidson's point, that it requires us to say of a murderous queen who dies before her poisoned victim that she is still killing him when she herself is dead. $^{42}$ But this sounds preposterous!

Moore proceeds to argue that although the oddities afflicting the short view can be explained away satisfactorily, the oddities afflicting the long view cannot. In defense of the short view, he says that a killing does not last until the victim's death; it is merely that the basic action that causes the death does not acquire the property "cause of death" (and hence the property of being a killing) until the death occurs. ${ }^{43}$ This by itself does not explain away Thomson's usage oddities, but Moore claims that these can be explained away as mere pragmatic oddities, for reasons partly discussed earlier. ${ }^{44}$ No comparably satisfactory explanations are available, claims Moore, of the oddities afflicting the long view. He writes:

I conclude that the location implications of either the extreme or the moderate fine-grained metaphysics of complex actions leads to absurdities that cannot be explained away, whereas the location implications of the coarse-grained metaphysics of complex actions lead only to apparent absurdities that can be explained away in a satisfactory manner. ${ }^{45}$

Although I am not fully persuaded that the balance of evidence favors the short view, as Moore claims, I am impressed by the need

${ }^{11}$ See Judith J. Thomson, The Time of a Killing, 68 J. PHIL. 115, 115-20 (1971).

12 See MOORE, supra note 1, at 285.

${ }^{43}$ See id. at 285-86.

${ }^{44}$ See supra part I.

${ }^{45}$ MOORE, supra note 1, at 292. 
for the law to adopt this position at least for some of its purposes. The simultaneity principle for murder, for example, requires that the intent to kill be simultaneous with the act of killing, and the courts have in this situation decided that the time of a killing is the same as the time of the basic action. ${ }^{46}$ But suppose, arguendo, that Moore is right that the short view of complex actions fares better on the whole. Does this decisively confirm the coarse-grained theory? Only if the fine-grained theory is totally wedded to the long view, as Moore clearly believes. He writes:

Where the policies behind legal doctrines require the asking of the metaphysical questions of when an action was done, the courts have located complex actions at their source, in the corresponding basic actions. Such location presupposes the coarse-grained metaphysics identifying complex actions with basic ones. ${ }^{47}$

Given the state of the literature in action theory, it may be reasonable of Moore to believe the emphasized sentence, asserting that only the coarse-grained theory can accommodate the short view. But although this belief may be reasonable, it is not correct.

It is true that what Moore calls the moderate fine-grained theory is committed to the long view. Indeed, Moore virtually defines "moderate fine-grained theory" as the view that complex acts have parts or components that include both basic acts and intermediate and final results of these acts picked out by complex action descriptions. ${ }^{48}$ But is the extreme fine-grained theory committed to the long view? ? $^{49}$ The crucial feature of this position (as I understand Moore's terminology) is that it not only regards pairs of acts like shooting and killing to be nonidentical, but also pairs of acts

${ }^{16}$ See id. at 299-300. As Moore points out, however, the law has other purposes for which killings are dated rather differently. In applying the statute of limitations, for example, the courts date killings from the time death occurs, not from the time of the basic action nor from the time of that action's first effects on the victim's body. See id. at 298.

${ }^{47}$ Id. at 300-01 (emphasis added).

18 Commentators who defend the componential view, which Moore equates with the "moderately fine-grained view," include LAWRENCE H. DAVIS, THEORY OF ACTION (1979); GINET, supra note 34; IRVING THALBERG, PERCEPTION, EMOTION AND ACTION (1977); Thomson, supra note 8; Monroe C. Beardsley, Actions and Events: The Problem of Individuation, 12 AM. PHL. Q. 263 (1975); Lawrence H. Davis, Individuation of Actions, 67 J. PHIL. 520 (1970); Thomson, supra note 41.

${ }^{49}$ The usually cited defenders of the fine-grained view are Jaegwon Kim and myself. See Kim, Events, supra note 18, at 159-63; Jaegwon Kim, Events and Their Descriptions: Some Considerations, in ESSAYS IN HONOR OF CARL G. HEMPEL 198, 198213 (Nicholas Rescher ed., 1970); Jaegwon Kim, On the Psycho-Physical Identity Theory, 3 AM. PHIL. Q. 227, 227-35 (1966). 
like saying "hello" and saying "hello" loudly. There is nothing in this practice of individuation, however, that constitutes a commitment to the componential view, so it remains open to defenders of the extreme fine-grained theory to take the short view rather than the long view on the question of temporal extent. ${ }^{50}$ If our earlier discussion is correct, there are already ample arguments against the coarse-grained theory and in favor of the fine-grained theory without appealing to temporal disparities. ${ }^{51}$ So a fine-grained theorist might join Moore in accepting the short view, although not for his reasons.

This point needs some clarification. The fine-grained theorist will not admit, of course, that the temporal span of a complex action matches that of its corresponding basic action simply because the complex action is the basic action. A fine-grained theorist will not concede this "because" statement at all. Nonetheless, she might admit that the respective temporal spans coincide. What considerations might support this position? According to the extreme finegrained theory, an action is a property-exemplification, or trope. So the temporal span or duration of an act-token must be the period over which the agent exemplifies the act-type in question. When does an agent exemplify the act-type of killing, or any other causally complex act? Does the exemplifying take place throughout the period until the final causal result has occurred? Or does the exemplifying occur just when the basic action that "level-generates" the complex action occurs? I am inclined to think that this is a rather indeterminate matter, which would explain why the courts have had such difficulties with these issues, as Moore documents. ${ }^{52}$ But I see no barrier to the fine-grained theorist's adopting the short view as slightly preferable on the whole. After all, what is a killing? At first approximation, it is a causing of death. When does such causing take place? It is plausible to say that the causing occurs at the same time as the pertinent basic action (that is, the basic action that level-generates the causing of death). This does not entail that the causing is the basic action (say, moving one's finger). The fine-

${ }^{50}$ For myself, I was deliberately rather noncommittal about temporal questions in A Theory of Human Action. See Goldman, Human Action, supra note 6, at 21-22, 3537, 45-46. In The Individuation of Action, I did endorse a temporal argument against the coarse-grained theory, and by implication I endorsed the long view of a killing; but this was in a brief paragraph which played a very minor and detachable role in the discussion. See Goldman, Individuation, supra note 6, at 767.

${ }^{51}$ See supra parts I-IV.

${ }^{52}$ See MOORE, supra note 1 , at 293-301. 
grained theory excludes this because it is an instance of the type causing death, not of the type moving one's finger. Thus, the killing may be simultaneous with the basic action without being identical to it. An analogous position may be adopted for spatial location. So even if the short view is right or preferable on the whole, as Moore contends, this does not refute the fine-grained approach. Since Moore treats the temporal and spatial arguments as the principal arguments against the coarse-grained theory, he might be surprised to find a fine-grained theorist willing to yield ground on the spatiotemporal questions. As we have seen, though, there are four types of arguments against the coarse-grained theory and in favor of the fine-grained theory, quite apart from the temporal and spatial arguments.

Let me conclude this Section with a different conjecture about spatiotemporal location. I suspect that our conceptualization of actions, including their spatiotemporal locations, is powerfully driven by features of the language used in ascribing or naming them. Since simple action ascriptions are of subject-predicate form, we conceive of an act's primary location as the place of the agent and the time of the agent's pertinent bodily movement. Some evidence for this is that when an action sentence or nominalization is put into passive form, the primary place and time seem to change. Intuitively, the primary location of Jones's-being-killed-by-Smith seems to be where Jones is, although the primary location of Smith's-killing-Jones seems to be where Smith is. Complex actions also seem to have secondary locations, however: namely, where the patients or objects of action are located. Perhaps complex actions have tertiary locations too: along the paths from agents to patients (or objects). Distinguishing between primary and secondary locations would explain why we have competing intuitions, pulling us alternately toward the short view and toward the long view. It would also partly explain the difficulties courts have had in finding a firm and consistent doctrine on the spatiotemporal locations of complex actions. This compromise position, however, only makes sense on the fine-grained theory. The coarse-grained theory is incompatible with the primary/secondary story, because the only location of a complex action, according to that theory, is the place of the agent and the time of the basic action. 


\section{OFFENSES AND DOUBLE JEOPARDY}

In this final Section, I want to illustrate how the fine-grained theory can be conceptually useful in the criminal law. Some of the most fascinating problems in the law that intersect with action theory are ones pertaining to the double-jeopardy requirement, which Moore discusses so intriguingly in part III of his book. The points I shall address arise in the context of the double-jeopardy issue.

The first point I wish to make concerns the notion of an "offense" as it occurs in the law. This notion has the same sort of type-token ambiguity as the notions of action and event. Clearly, drunk driving, wrong-side-of-the-road driving, and excessively speedy driving are all types of offense, so the notion of an offense-type is uncontroversial. But it is also evident that "offense" sometimes refers to act-tokens. For example, when the federal constitution says that no person shall "be subject for the same offence to be twice put in jeopardy of life or limb," 53 it is clearly talking about offensetokens. It obviously does not mean that no person shall be twice punished or put in jeopardy of punishment for the same offensetype, since a person might commit the same offense-type on several separate occasions and be separately punishable for each. Granted, then, that the law uses the notion of an offense-token, the question whether it can be adequately captured by the coarse-grained theory arises. I think not.

The only candidate for being an offense-token is being an acttoken. Under the coarse-grained theory this simply amounts to being a basic action, or bodily movement. But this does not adequately capture the legal notion of an offense-token, because a person might perform multiple offense-tokens via the performance of a single coarse-grained action. We might have an instance of drunk driving, an instance of wrong-side-of-the-road driving, and an instance of excessively speedy driving, and these would be three different offense-tokens all wrapped up in a single coarse-grained action. Thus, the coarse-grained theory by itself lacks the resources for satisfactorily capturing the notion of offense-tokens. The finegrained approach, by contrast, easily accommodates the notion of an offense-token. Since John's driving while drunk, John's driving on the wrong side of the road, and John's driving at excessive speed

${ }^{53}$ U.S. CONST. amend. V. 
are all distinct act-tokens, each violating a distinct statute, it is easy to count each as a distinct offense-token.

The problem facing the coarse-grained theory in addressing double-jeopardy problems is perhaps most dramatic in Moore's case of Smith killing both Jones and Long with a single shot (and a single basic act). As Moore notes, Smith did much more wrong in killing both Jones and Long than he would have done if he had killed Jones only. So Smith deserves more punishment, because of more wrongdoing. The problem for the coarse-grained theory is how it can accommodate this notion of greater wrongdoing. There seems to be only one wrong act-type his act-token instantiates, namely, killing another human being. This suggests that Smith did this one wrong (killing) more than once, that is, he performed more than one token of this type. But this option is unavailable to the coarse-grained theory because the theory entails that there is only one act-token here..$^{54}$

Given the (limited) resources of his metaphysics, Moore offers a creative solution to his difficulty. He suggests that two morally wrong act-types are instantiated by Smith, viz., killing Jones and killing Long. For these purposes, he says, we should individuate types, not only by their character (killing, for example), but also by their victims. ${ }^{55}$ Although this creative solution may work satisfactorily for the problem at hand, it still omits something that seems intuitively right, namely, that Smith performs two offense-tokens in killing both Jones and Long. This is easily captured by the fine-grained theory, which makes its treatment of the case preferable, in my opinion.

Additional evidence for the fine-grained theory (or against a monolithic coarse-grained theory) comes from the language used by the court in formulating the common-law merger doctrine, which is a court-created rule of statutory construction whereby multiple punishment under two or more offenses is banned where such offenses are committed by a single "act, transaction, or episode. ${ }^{n 56}$ It is noteworthy that the court offered several terms here to capture its intended meaning. Apparently it did not feel that "act" would unambiguously capture what it meant to pick out-roughly, a coarsegrained action. So it offered the alternate terms, "transaction" and "episode," to help convey its meaning. I suspect that this is because the court rightly felt that "act" can be taken, and is perhaps more

\footnotetext{
54 See MOORE, supra note 1 , at 361 .

${ }^{55} \mathrm{See}$ id. at 362.

${ }^{56}$ Commonwealth v. Williams, 496 A.2d 31, 41-42 (Pa. Super. Ct. 1985).
} 
naturally taken, to refer to a fine-grained entity. Thus, the court's language lends some support to the fine-grained view.

At the same time, it must be acknowledged that courts also have reason to refer to something like a coarse-grained action. This is, after all, the sort of thing intended by the phrase "act, transaction, or episode." It is essential to statutory formulations of double jeopardy, for example, that people not be punished for lesser included offenses of a main charge if they involve "the same act." The phrase "same act" cannot here refer to a finely-individuated act, because this would allow someone to be punished for committing both battery and aggravated battery, two different fine-grained tokens, despite throwing just one punch. In other words, finegrained individuation threatens to yield too many act-tokens for double-jeopardy purposes; the doctrine needs some way of capturing what the coarse-grained theory seeks to capture with its conception of action individuation.

The resources for expressing this conception, however, are readily available within the fine-grained theory. Specifically, one can identify the coarse-grained conception of a single act with the lowest basic act at the root of a fine-grained act-tree, or perhaps with an entire act-tree. ${ }^{57}$ In other words, what the coarse-grained theory calls a "single act" is the class of finely individuated acts that are either level-generated by or identical to a single basic act. Thus, the doctrine that people are not punishable for lesser-included offenses of "the same act" might be rendered in the following fine-grained terminology: "People should not be punished both for a greater offense-token and for a lesser-included offense-token where both of those offense-tokens are level-generated by or identical to the same basic act-token." This seems to capture the intended principle in thoroughly fine-grained fashion. It appears, then, that the finegrained theory is a superior theory, both for metaphysics generally and for the purposes of the law. The coarse-grained theory, which Moore endorses, cannot satisfy all pertinent desiderata. ${ }^{58}$

${ }^{57}$ See Goldman, Human Action, supra note 6, at 33-37, 56-60.

${ }^{58}$ An alternative approach is a "double-entity" approach, which would acknowledge the existence of both fine-grained and coarse-grained actions (and where the latter are not "reduced" to trees of fine-grained actions). Perhaps this double-entity approach is supported by the evidence from linguistics. In terms of theoretical economy, however, a single-entity approach is preferable, and of the two options, the fine-grained approach satisfies more desiderata, avoids more difficulties, and is more useful in the context of the criminal law. 